4. Acemoglu D, Robinson JA. ¿Por qué fracasan los países? 1ra edición. Bogotá, Colombia: Deusto S.A. Ediciones; 2012.

5. Rodríguez-Morales AJ, Henao DE, Franco TB, MaytaTristán P, Alfaro-Toloza P, Paniz-Mondolfi AE. Ebola: a latent threat to Latin America. Are we ready? Travel Med Infect Dis. 2014 Nov-Dec;12(6 Pt A):688-9. doi: 10.1016/j. tmaid.2014.11.002.

Correspondencia: Daniel Eduardo Henao Nieto

Dirección: Jardin 2 M 14 C 14 Pereira, Colombia

Teléfono: 573137351058

Correoelectrónico:d.henao@utp.edu.co

\section{IMPACTO DEL FENÓMENO “EL NIÑO" DE 1997-1998 EN LA SALUD DE LA POBLACIÓN PERUANA, RIESGO POTENCIAL PARA EL 2015}

\author{
IMPACT OF THE "EL NIÑO" PHENOMENON \\ FROM 1997 TO 1998 ON THE HEALTH OF THE \\ PERUVIAN POPULATION: RISK POTENTIAL \\ FOR 2015
}

\section{Luis Suarez-Ognio ${ }^{1, a}$, David Estela-Ayamamani ${ }^{1, b}$, Brenda Cáceres-Mejía ${ }^{1, b}$, Carlos Gambirazio-Carbajal ${ }^{1, \mathrm{c}}$, Rufino Cabrera ${ }^{1 \mathrm{~d}}$}

Sr. Editor. El National Oceanic and Atmospheric Administration de los Estados Unidos y el Servicio Nacional de Meteorología e Hidrología del Perú han comunicado que en el 2015 se presentará un nuevo fenómeno "El Niño" (El Niño Oscilación Sur-ENSO). Este fenómeno produce elevación de la temperatura ambiental y un incremento de las precipitaciones pluviales (1); ocasionando inundaciones y aluviones ("huaycos") como consecuencias inmediatas y posteriormente alteración del ecosistema favoreciendo el incremento de la vegetación y la aparición de plagas de insectos y roedores.

ENSO favorece la transmisión de enfermedades infecciosas. En 1997-1998 se observó un incremento en general de las enfermedades diarreicas agudas

\footnotetext{
1 Escuela de Medicina, Universidad Peruana de Ciencias Aplicadas. Lima, Perú.

a Médico especialista en epidemiología ; ${ }^{b}$ médico cirujano; ${ }^{c}$ médico veterinario; ' biólogo

Recibido: 31-03-15 Aprobado: 22-04-15
}

Citar como: Suarez-Ognio L, Estela-Ayamamani D, Cáceres-Mejía B, Gambirazio-Carbajal C, Cabrera R. Impacto del fenómeno "El Niño" de 1997-1998 en la salud de la población peruana, riesgo potencial para el 2015 [carta]. Rev Peru Med Exp Salud Publica. 2015;32(2):403-4.
(EDA) y de la actividad epidémica de cólera después del descenso progresivo observado de 1991 a 1996; durante las primeras 26 semanas de 1997 se notificaron 1080 casos, y 34306 en $1998^{(1,2)}$. Favorecieron también el incremento de los casos de cólera y EDA el:

- Colapso de los sistemas de agua y alcantarillado.

- Incremento del consumo de agua no segura.

- Deterioro de los sistemas de conservación de alimentos.

- Formación de conglomerados sociales en albergues con deficiente saneamiento.

- Implementación de "ollas comunes" para la preparación de alimentos, incrementando la posibilidad de brotes por una fuente común.

- Incremento de la venta ambulatoria de alimentos sin adecuadas medidas de conservación.

Aunque hace más de una década no se presentan casos de cólera en el Perú, las condiciones climáticas y la actual presencia de cólera en el continente incrementan el riesgo de reingreso al país.

Otro problema que emergió durante el año 1998 fue el denominado "golpe de calor" ${ }^{(3)}$, el cual afectó principalmente a niños y ancianos en diferentes departamentos de la costa peruana. Se presentaron plagas del insecto Paederus irritans en Piura y Lambayeque ocasionado brotes de una dermatitis de contacto dolorosa a la que la población denominó "latigazo" (4). También se produjo la aparición de especies marinas de agua caliente cerca de la costa, como el Coryphaena hippurus "perico", que se encontraba con un elevado parasitismo por Anisakis sp. que produjo casos de anisakiosis en humanos ${ }^{(5)}$.

Los pobladores que estuvieron expuestos al agua y lodos de las inundaciones presentaron enfermedades de la piel, en especial casos de dermatitis infecciosa. Por otro lado, se observó un incremento significativo de los casos de malaria en la costa norte ${ }^{(1,2)}$. La elevación de temperatura favoreció la reproducción de artrópodos transmisores de enfermedades como Aedes aegypti y Anopheles.

Es importante que las autoridades del sector salud y del Instituto Nacional de Defensa Civil tomen medidas preventivas y se anticipen a los potenciales riesgos epidémicos de un nuevo ENSO. El contexto actual se ve agravado por los brotes de dengue con serotipos de reciente ingreso al país, además del inminente ingreso del virus del chikungunya. Las autoridades sanitarias, así como las instituciones encargadas de tomar medidas de prevención tienen un importante rol en la vigilancia, la investigación y el control de estos potenciales problemas sanitarios. 
Fuentes de financiamiento: autofinanciado.

Conflictos de interés: declaramos no tener conflictos de interés

\section{REFERENCIAS BIBLIOGRÁFICAS}

1. Organización Panamericana de la Salud. Fenómeno El Niño, 1997-1998. 1a ed. Washington, DC.: OPS; 2000.

2. Perú, Ministerio de Salud, Organización Panamericana de la Salud. Fenómeno El Niño 1997-1998: Informe oficial del Ministerio de Salud del Perú. Lima: MINSA; 1999.

3. Miranda JJ, Cabezas C, Maguiña C, Valdivia M. Hipertemia durante el fenómeno de El niño, 1997-98. Rev Peru Med Exp Salud Publica. 2003;20(4):200-5.

4. Alva-Davalos V, Laguna-Torres VA, Huaman A, Olivos R, Chavez M, Garcia C, et al. [Epidemic dermatits by Paederus irritans in Piura, Perú at 1999, related to El Niño phenomenon]. Rev Soc Bras Med Trop. 2002 Jan-Feb;35(1):23-8. [Artículo en portugués].

5. Cabrera R, Suárez-Ognio L, Martínez R, Leiva R, Gambirazio C, Ruiz J. Larvas de Anisakis physeteris y otros helmintos en Coryphaena hippurus "perico" comercializados en el mercado pesquero de Ventanilla, Callao, Perú. Rev Peru Biol. 2002;9(1):1-8.

Correspondencia: Luis Suarez Ognio.

Dirección: Parque Almagro 140. Jesús María.

Teléfono: 949712749

Correo electrónico:luis.suarez@upc.edu.pe

\section{EVALUACIÓN DE TRES MARCAS COMERCIALES DE PRUEBAS RÁPIDAS PARA LA DETECCIÓN DE VIH}

\section{EVALUATION OF THREE COMMERCIAL BRANDS OF HIV RAPID TESTS}

\section{Eduardo Miranda-Ulloa, ,a, Soledad Romero-Ruiz ${ }^{1, b}$ Ronal Briceño-Espinoza ${ }^{1, \mathrm{c}}$, Daniel Santos-Anaya ${ }^{1, \mathrm{~d}}$}

Sr. Editor. Uno de los principales problemas en las zonas rurales de Perú es la transmisión vertical del $\mathrm{VIH}$. El problema aumenta cuando las gestantes por diferentes causas no acuden a los servicios de salud, por lo que el personal de salud se ve en la obligación de realizar labores de visitas domiciliarias. En la actualidad, el Ministerio de salud (MINSA) usa pruebas rápidas

\footnotetext{
Laboratorio de Referencia Nacional Virus de Transmisión Sexual VIH/ SIDA, Centro Nacional de Salud Pública, Instituto Nacional de Salud. Lima, Perú.

a Biólogo, magíster en Microbiología; ${ }^{\mathrm{b}}$ biólogo, microbiólogo, doctora en Salud Pública; ${ }^{c}$ estudiante de Tecnología médica y técnico de laboratorio; ${ }^{\mathrm{d}}$ tecnólogo médico.

Recibido: 04-04-15 Aprobado: 22-04-15
}

Citar como: Miranda-Ulloa E, Romero-Ruiz S, Briceño-Espinoza R, Santos-Anaya D. Evaluación de tres marcas comerciales de pruebas rápidas para la detección de VIH [carta]. Rev Peru Med Exp Salud Publica. 2015;32(2):404-5. inmunocromatográficas de tercera generación para atender el diagnóstico en estas zonas rurales, es decir solo detectan anticuerpos contra el VIH. Últimamente, han aparecido pruebas rápidas inmunocromatográficas comerciales de cuarta generación, es decir, que detectan simultáneamente antígeno p24 y anticuerpos de $\mathrm{VIH}$, acortando de esta manera el periodo de ventana. La presencia de antígeno p24 nos indicará una infección temprana del VIH.

Con el propósito de conocer la marca con mayor eficiencia diagnóstica es que se evaluó la reactividad de tres marcas de kits comerciales de pruebas rápidas inmunocromatográficas diseñadas para la detección simultánea de antígeno p24 y anticuerpos de $\mathrm{VIH}$. Durante el segundo semestre del 2013 se realizó un estudio de evaluación de prueba diagnóstica cualitativa. Las marcas evaluadas fueron: Alere Determine TM - HIV- 1/2 Ag/Ab Combo (1), SD Bioline HIV Ag/Ab Combo (2) y Onsite HIV Ab/Ag 4ta Gen Rapid Test (3). Estas tres marcas fueron escogidas debido a que ya se usan en Perú en algunos centros de salud particulares y organizaciones no gubernamentales (ONG).

Para la evaluación, se seleccionó de la Seroteca del Laboratorio de Referencia Nacional de VTS VIH/SIDA, 163 sueros, de los cuales 43 sueros fueron positivos a antígeno p24 confirmados por EIA Innotest HIV Antigen mAb Neutralization Reagents (4) (prueba gold estándar para Ag p24), 60 sueros fueron positivos y 60 negativos a anticuerpos contra VIH confirmados por Inmunoensayo en Línea (LIA) ${ }^{(5)}$ (prueba gold estándar para anticuerpos). Para evitar sesgos todos los sueros fueron reconfirmados previos a la evaluación con las pruebas rápidas en estudio. Para el análisis inmunocromatográfico las tres marcas utilizaron anticuerpo monoclonal anti VIH-p24; en relación al tipo de antígeno usado, la marca Onsite usa antígenos recombinantes gp 120 y gp 41 de $\mathrm{VIH}-1$ y gp 36 de $\mathrm{VIH}-2$, sin embargo, las marcas Alere y SD no especifican en sus insertos qué tipo de antígenos utilizan, solo mencionan que usan antígenos recombinantes para $\mathrm{VIH}-1 / 2$.

Los ensayos fueron realizados según la metodología especificada en los insertos de cada marca. Las lecturas de las tres marcas incluyeron una banda para Ag p24 y una banda para anticuerpos. En el presente estudio, la sensibilidad y especificidad diagnóstica hallada para la detección de anticuerpos para las tres marcas fue de $100 \%$. La sensibilidad diagnóstica hallada para la detección de Ag p24 de Alere Determine, SD Bioline y Onsite fueron: $54,8 \%, 47,6 \%$ y $14,3 \%$ respectivamente. (Tabla 1 ).

En relación a la sensibilidad y especificidad diagnóstica hallada para la detección de anticuerpos, los resultados demuestran que no existen diferencias con lo presentado 